\title{
Gigantol from Dendrobium chrysotoxum Lindl. binds and inhibits aldose reductase gene to exert its anti-cataract activity: an in vitro mechanistic study
}

Jie Wu ${ }^{1 \#}$, Xue Li ${ }^{1 \#}$, Wencheng Wan ${ }^{1}$, Qiaohong Yang ${ }^{1}$, Weifeng Ma ${ }^{1}$, Dan Chen ${ }^{1}$, Jiangmiao $\mathrm{Hu}^{2}$, C.-Y. Oliver Chen ${ }^{3}$, Xiaoyong Wei ${ }^{1,3, *}$

Affiliation

1. School of Basic Medical Sciences, Guangzhou University of Chinese Medicine, Guangzhou, 510006, China.

2. State Key Laboratory of Phytochemistry and Plant Resources in West China,

Kunming Institute of Botany, Chinese Academy of Sciences, Kunming 650204, China

3. Antioxidants Research Laboratory, Jean Mayer USDA Human Nutrition Research

Center on Aging, Tufts University, Boston, MA 02111, USA

${ }^{\#}$ Equal contribution to this study

*Corresponding author

Xiaoyong Wei: School of Basic Medical Sciences, Guangzhou University of Chinese Medicine, Guangzhou 510006, China. Email: jidewowxy2@163.com; Tel: 13113989538. 


\section{Introduction}

Diabetic cataract (DC) is a major cause of blindness in patients with diabetes (Minassian and Mehra, 1990; Wild et al., 2004; Pascolini and Mariotti, 2011; Rao et al., 2011; Bahmani et al., 2012; Nasir et al., 2013). While the development and progression of DC is caused by multifactorial mechanisms, the polyol pathway has been recognized as one of the most important mechanisms (Srinivasan et al., 2012; Miyamoto, 2002; Yabe-Nishimura, 1998). Aldose reductase (AR) is the first and rate-limiting enzyme in the polyol pathway; thus, genetic polymorphisms of this enzyme impose genetic susceptibility to DC (Chung SS and Chuang SK, 2003; Wang Y et al, 2014; Li et al., 2015). High blood glucose levels can induce AR gene expression in human lens epithelial cells, and lead increased sorbitol production from glucose via the polyol pathway (Gudipudi, G et al., 2016; Susen and Buyukbingol, 2003; Judy and Stanley, 1986). The resulting sorbitol production increases osmotic pressure, changes cell membrane permeability, and promotes the development of cataracts (Henry et al., 1993).

In traditional Chinese medicine, Shihu is a famous and precious Chinese herbal medicine derived from different species of Dendrobium, including D. chrysotoxum Lindl., D. nobile Lindl., and $D$. fimbriatum Hook. Shihu has been used to prepare various medicinal and health products in many Asian countries. D. chrysotoxum Lindl. is a commonly used species of medicinal Dendrobium (Shihm), indexed in the Chinese Pharmacopoeia (Commission of Chinese Pharmacopoeia, 2010). Many ancient books e.g. "Shennong's Herbal", "Compendium of Materia Medica", "Supplement to compendium of materia medica", have been recorded its traditional treatment of nourishing yin and clearing heat, tonifying stomach and promoting fluid, improve eyesight (Pan et al., 2014). While the therapeutic potential for cataracts may be attributed to an additive/synergistic effect of 
constituents in D. chrysotoxum Lindl (Fang et al., 2015). Gigantol (Yang et al., 2006; Fan et al., 2014, Wu et al., 2015), extracted from D. chrysotoxum Lindl., was found to exert anti-DC effects through the inhibition of $\mathrm{AR}$ activity down-regulation of $\mathrm{AR}$ gene expression in a galactose-induced cataract rat (Fang et al., 2015). However, the mechanisms underlying gigantol and AR gene interaction remain unclear. In this study, the human lens epithelial cells (HLECs) were cultured in $50 \mathrm{mM}$ glucose medium to further validate gigantol curative effects. Reverse transcription polymerase chain reaction (RT-PCR) analysis showed that gigantol suppressed AR gene transcription in HLECs, and various biophysical tools were used to further monitor direct interaction of gigantol and the AR gene, including Ultraviolet-visible spectroscopy (UV spectra),

atomic force microscopy (AFM), and surface-enhanced Raman spectroscopy (SERS). Our findings provide insights on the mechanisms of gigantol and AR gene at the molecular level, as well as a comprehensive theoretical basis for the use of Dendrobium as anti-DC.

\section{Materials and Methods}

\subsection{Reagents and instruments}

Glucose and $\gamma$ - aminopropyl triethoxysilane (APTES) were purchased from Aladdin Reagent Co. (Shang Hai, China); the HLECs (Ibarki et al., 1998) line SRA01/04 was a gift from the Ophthalmology Center of Sun Yat-Sen University (P.R. China). Minimum essential medium (MEM), Penicillin-Streptomycin and 0.25\% Trypsin were purchased from Gibco (Grand Island, USA); Fetal bovine serum (FBS) from Biological Industries (Israel), mica from Tosai (Japan), and TRIzol reagent from Invitrogen (New Zealand). The plasmid pcDNA3.1 (-)-N1 was provided by Guangxian Zhang, Ph.D (GuangZhou University of Chinese Medicine, China). The 
Endo Free Plasmid Maxi kit and DNA Gel Extraction kit was purchased from Sagene Biotech Co.

(Guanghzou, China). The Prime STAR ${ }^{\mathrm{TM}}$ HS DNA Polymerase kit was purchased from Takara (Japan). The plasmid pET28a-AR was purchased from Landbiology Co. (Guangzhou, China), the T4 DNA Ligase and the restriction enzymes BgIII and EcoRI from Takara Biotechnology, Co., Ltd (Japan). All-in-One ${ }^{\mathrm{TM}}$ qPCR Mix was purchased from GeneCopoeia (MD, USA). UV spectra was recorded using an Ultrospec 3300 pro UV-visible spectrophotometer (Biochrom Ltd, England), AFM images were taken using a Bruker MultiMode 8 scanning probe microscope (Germany), and SERS were recorded using a Micro-Raman spectrometer (H.J.Y. Company, French). The centrifugation in the experiment was used High speed refrigerated centrifuge, HR/T16M (Changsha, China).

\subsection{Gigantol extraction}

The stems of Dendrobium chrysotoxum Lindl were collected from Puer municipal, Yunnan province, P.R. China and identified by Professor Hong Yu of the Yunnan University, Kunming, P.R. China. Voucher specimens (NO. Zsh-2 and Zsh-5) were preserved at the State Key Laboratory of Phytochemisty and Plant Resource in West China, Kunming Institute of Botany, Chinese Academy of Sciences. P.R. China. Gigantol was extracted from Dendrobium chryostoxum Lindl, according to the method of $\mathrm{Hu}$ et al with some minor modifications (Hu JM et al., 2012). The air dried stems of Dendrobium chrysotoxum (7.6kg) were powdered and extracted with 95\% aqueous $\mathrm{EtOH}(38 \mathrm{~L} \times 3)$ under reflux; the $\mathrm{EtOH}$ extract $(105 \mathrm{~L})$ was evaporated under reduced pressure and fractionated successively into EtOAc soluble (250g) and $\mathrm{n}-\mathrm{BuOH}$ soluble (249 g) fractions; EtOAc extract was subjected to column chromatography 
(CC) (silica gel (200-300 mesh, 3000g), petroleum ether/Me2CO (7:3 -0:10)) to give fractions I

-VI; Fraction III (26.0 g) was subjected to CC (silica gel, petroleum ether/Me2CO(4:1)) to afford fractions a-e, then the fraction c (5.4g) was purified by CC (sephadex LH-20, CHCl3/MeOH, 1:1, v/v) to afford compounds gigantol (3.5g) (Hu JM et al., 2012).

\subsection{HLECs culture and experimental groups}

HLECs were cultured in MEM supplemented with 20\% FBS and 1\% penicillin streptomycin at $37^{\circ} \mathrm{C}$ in a humidified environment containing $5 \% \mathrm{CO}_{2}$. The culture medium was changed after 24 hours and then every alternate day. Confluent cells were washed with phosphate-buffered saline (PBS), harvested and seeded at a density of $1-2 \times 10^{5}$ cell/well. Twenty-four hours after seeding, the treated cells were grouped with control group (5.56mmol/1 glucose-MEM, A), model group (50mmol/1 glucose-MEM, B), and gigantol group (50mmol/1 glucose-MEM $+1 \mu \mathrm{g} / \mathrm{mL}$ gigantol, C) for 24 hours. Experiments were performed in triplicate.

\subsection{RT-PCR}

Total RNA was extracted and purified from HLEC using the TRIzol reagent, according to the manufacturer's instructions. RNA counts were quantified by measuring the absorbance at $260 \mathrm{~nm}$. Samples with OD260/280 $\mathrm{nm}$ greater than 1.8 were used. RT-PCR was performed using All-in-One ${ }^{\mathrm{TM}}$ qPCR Mix. In general, total RNA $(1 \mu \mathrm{g})$ was added to a $20 \mu \mathrm{L}$ reaction mixture for the reverse transcription; all PCR procedures were performed according to the manufacturer's instructions. The primers used in this study were: AR, 5'CTTCCCTCCCTATCTAACCCT3' and

5'TCTAAACTTCCCGTGGCATAA3'; $\beta$-actin, 5'-GAGACCTTCAACACCCAGCC-3' and 5'-GCGGGGCATCGGAACCGTCA-3'. The cycling condition was: 30 cycles at $98^{\circ} \mathrm{C}$ for $10 \mathrm{sec}$ 
(denaturation), $58^{\circ} \mathrm{C}$ for $15 \mathrm{sec}$ (annealing), and $72^{\circ} \mathrm{C}$ for $1 \mathrm{~min}$ (extension). Gene expression was normalized to $\beta$-actin mRNA content.

\subsection{Preparation of AR gene solution}

The AR gene was prepared according to the method of Shao (Shao et al., 2015). The purified PCR products of AR gene which was amplified from the pET28a-AR plasmid and the plasmid pcDNA3.1 (-)-N1 were digested by the BgIII and EcoRI restriction enzymes for six hours at $37^{\circ} \mathrm{C}$, respectively. The digestion products were purified and isolated, and the target gene (AR gene) was then subcloned into the pcDNA3.1 (-)-N1 vector using T4 DNA ligase, forming the recombinant plasmid pcDNA3.1 (-)-N1-AR. DNA was extracted from plasmid bacteria pcDNA3.1 (-)-N1-AR by use of the Endo Free Plasmid Maxi kit. The target AR gene was separated from plasmid on $0.8 \%$ for agarose gel electrophoresis, taking the DL 1,000 DNA Marker as the reference, then recycled gel with the AR gene. PCR amplification was conducted in a $25 \mu \mathrm{L}$ volume, using Prime $\mathrm{STAR}^{\mathrm{TM}} \mathrm{HS}$ DNA Polymerase kit according to the manufacturer's instructions. Each assay contained $1 \mu \mathrm{L}$ plasmid DNA. Primers were designed by Sangon Biotech Co., Ltd (Shanghai, China) and were selected to amplify AR gene fragments (Table 1). After the plasmid DNA was denatured for $1 \mathrm{~min}$ at $94^{\circ} \mathrm{C}$, amplification conditions consisted of 30 cycles of $10 \mathrm{~s}$ at $98^{\circ} \mathrm{C}$ and $15 \mathrm{~s}$ at $58^{\circ} \mathrm{C}$ followed by extension at $72^{\circ} \mathrm{C}$ for $1 \mathrm{~min}$. The reaction was concluded with a final extension at $72^{\circ} \mathrm{C}$ for $10 \mathrm{~min}$. At last, the purified $\mathrm{AR}$ gene solution was obtained by use of the DNA Gel Extraction kit.

\subsection{UV-visible spectroscopy}

UV-visible spectra of gigantol and AR gene were monitored at 220-320 nm (Banitaba et al., 
2011). AR gene solution $\left(10^{-7} \mathrm{M}\right)$ in $0.01 \mathrm{M}$ Tris-Hcl buffer (PH7.4) was added to $4.5 \mathrm{~mL}$ colorimetric tubes and then mixed with $2 \mu \mathrm{L}$ of selected concentrations of gigantol. $0.01 \mathrm{M}$ Tris-Hcl buffer (PH7.4) was used as the blank control. The binging constant between AR gene and gigantol was calculated by the double-reciprocal formula (1) (Ouameur et al., 2005); and the Gibbs free energy $(\Delta \mathrm{rGm})$ of the reaction was estimated from equation (2), and the reaction could proceed spontaneously and exergonic if the $\Delta \mathrm{rGm}$ is negative (Daikos $\mathrm{O}$ et al., 2016).

$$
\begin{aligned}
& 1 /(\mathrm{A} 0-\mathrm{A})=1 / \mathrm{A} 0+1 /(\mathrm{Ka} \times \mathrm{A} 0 \times \mathrm{cDNA}) \\
& \Delta \mathrm{rGm}=-\mathrm{RT} \operatorname{lnKa}
\end{aligned}
$$

where A0 and A are the absorbance value of AR gene at $280 \mathrm{~nm}$ in the absence and presence of gigantol, respectively; $\mathrm{Ka}$ is referred to the binding constant; $\mathrm{Ka}$ is the binding constant at the corresponding temperature, and $\mathrm{R}$ is the gas molar constant.

\subsection{Atomic force microscopy}

Fresh APTES modified mica, was prepared, according to previous studies (Prasad A et al., 2016). AR gene solution was diluted with ultra-pure water to $5 \mathrm{ng} / \mu \mathrm{L}$; gigantol was diluted with ultra-pure water to $10^{-4}, 10^{-5}$, and $10^{-6} \mathrm{M}$ solution. A total of $2 \mu \mathrm{L}$ AR gene solution was added to $8 \mu \mathrm{L}$ of gigantol solution. The final concentration of AR gene was $1 \mathrm{ng} / \mu \mathrm{L}$. The resulting mixtures were incubated for $30 \mathrm{~min}$ at $37^{\circ} \mathrm{C}$. At the end of the incubation, the reaction mixture was dispensed onto the APTES modified mica plate, followed by the incubation for $10 \mathrm{~min}$ at room temperature. After rinsed for 5 6 times with ultra-pure water, the plates were air dried and stored in a dry container until analysis. Experiments were carried out at room temperature and detected using tapping mode imaging. 


\subsection{Surface enhanced Raman spectroscopy}

The microwave heating method was used for the preparation of silver colloid (Kang QQ et al., 2012; Zhang et al., 2005), using citric acid sodium to reducing silver nitrate to yield silver colloids with uniform particle size. The silver gum solution was obtained after centrifugation for 5 min at 12,000 rpm. The supernatant was discarded and the particles were then resuspended in deionized water, followed by ultrasonic cleaning for $5 \mathrm{~min}$. The nano silver particles were washed with deionized water for three times to generate the final product with a higher concentration and purity. The AR gene and gigantol mixes were prepared by mixing $10 \mu l$ of $0.9 \mu \mathrm{g} / \mathrm{L}$ AR gene with $10 \mu \mathrm{L}$ gigantol at the concentration of $10^{-5}, 10^{-6}$ or $10^{-7} \mathrm{M}$. To the resulting mixtures, Ag glue solution was added at the equal volume. Experimental excitation wavelength of $633 \mathrm{~nm}$ was applied for $5 \mathrm{sec}$ with 1 time exposure and a $50 \times$ magnification.

\subsection{Statistical analysis}

Statistical analyses and data processing were performed using SPSS 22.0 software. All data are expressed as mean $\pm \mathrm{SD}$. $\mathrm{P}<0.05$ was considered statistically significant.

\section{Results}

\subsection{AR gene expression in HLECs}

AR gene expression was increased by glucose by 2.2 fold compared to the control group (Fig. 1). But gigantol can significantly down-regulated the AR gene expression in HLECs by 1.35 fold compared to the model group (Fig. 1).

\subsection{Mode of interaction between gigantol and AR gene}

We used UV-visible spectroscopy to investigate the absorbance spectra of AR gene in the 
presence of increasing concentrations of gigantol. The characteristic peaks of AR gene were observed in the range of near $262 \mathrm{~nm}$. But on subsequent addition of gigantol to AR gene, the absorbance was gradually increased, indicating the hyperchromicity (Fig.2).

AR gene and gigantol interactions in UV-visible spectra appear as red shift in maximum absorption peak. At fixed AR gene concentrations, gradual addition of gigantol results in $260 \mathrm{~nm}$ absorbance change (Fig.3), binging constant between AR gene and gigantol was derived as $\mathrm{Ka}=$ $1.85 \times 10^{3} \mathrm{~L} / \mathrm{mol}$; and, $\Delta \mathrm{rGm}=-1.86 \times 10^{3} \mathrm{~J} / \mathrm{mol}$, which means that the reaction between gigantol and AR gene could proceed spontaneously. Form the red shift in UV-visible spectra indicated that the intercalative binding is most likely the dominant mode of the interaction between AR and gigantol.

\subsection{Effect of gigantol on surface morphology of AR gene}

To understand the cause of the interaction signal between gigantol and the AR gene in the UV-visible spectroscopic upon AR gene-gigantol binding, a series of tapping mode AFM images of AR gene were recorded with increasing concentrations of gigantol (Fig.4 and Fig.5). We can clearly saw that the AR gene was adsorbed on mica sheet surface by linear winding, the average height of AR gene computation for $1.2 \mathrm{~nm}$ (Fig.4). After the AR gene interacted with gigantol, AR gene was cut into many fragments of varying sizes (Fig.5-A1), With increasing of gigantol concentrations, part of the AR gene started winding, forming spiral rings, even remaining together. Average height increased by about 0.3-0.6 nm s (Fig.5-B1, C1).

\subsection{The results of SERS for interaction between gigantol and AR gene}

The interaction with gigantol and AR gene was characterized by SERS. And the SERS spectrum 
for gigantol and AR gene is shown in Fig. 6. The main bands were observed at Raman shifts: $422.63,1143.29,1264.98,1391.20,1576.39,2116.81,2920.27 \mathrm{~cm}^{-1}$. From these, the modes at $2920 \mathrm{~cm}^{-1}$ are assigned to stretching vibrations of aliphatic $\mathrm{CH}$ groups. And the strongest SERS peak was located $2122.10 \mathrm{~cm}^{-1}$ and $2122.86 \mathrm{~cm}^{-1}$ for the AR gene and gigantol. In this experiment, the SERS peaks of AR gene had practically no signals, but there were appearing some peaks in the absence of gigantol. Once gigantol was added, the typical peaks of AR gene were detected. With the increasing amounts gigantol, the peaks of AR gene were greatly enhanced.

\section{Discussion}

In this work, it provided the evidence of binding mode of AR gene and gigantol to reveal the interaction between AR gene and gigantol. It indicated that the dominant binding mode of AR gene and gigantol was the intercalate binding. Our findings on the interactions of gigantol with AR gene had been studied using UV-visible spectra, AFM and SERS.

As we know, UV-visible spectra is a classical method for studying interactions between small molecules and DNA (Guo et al., 2007, Ouameur A. A. et al., 2005). In this experiment, we found that the red-shift was happened at the interaction of AR gene and gigantol. And the role of DNA and small molecules in UV-visible spectra will cause changes in maximum absorption peak and intensity change to induce the red shift/blue shift, or hyperchromicity/hypochromicity, which can help uncover the interaction mode between small molecules and DNA (Dehkordi et al., 2012; Jaumot and Gargallo, 2012). In addition, the red shift would appear at the intercalative binding between small molecules and DNA (Niu et al., 2015; Pakravan and Masoudian, 2015; Tysoe et 
al., 1993). This might indicate that gigantol was inserted into the AR gene base pairs. In addition, from the binding constant $\mathrm{Ka}\left(1.85 \times 10^{3} \mathrm{~L} / \mathrm{mol}\right)$ and $\Delta \mathrm{rGm}\left(-1.86 \times 10^{3} \mathrm{~J} / \mathrm{mol}\right)$, indicated that the reaction of gigantol and AR gene was spontaneous (Gao and Liu, 2002).

To further characterize the interaction of gigantol and the AR gene, AFM was employed to investigate the surface morphology change of AR. AFM could observed the DNA molecular structure in vitro at room temperature and dry air condition (Xu J et al., 2016; Zheng, 2006). From the images of AFM, we observed that AR gene was forming many fragments of varying sizes after the interaction of AR gene and gigantol. The results of AFM provided great help in further identifying the binding interaction of the small molecule with DNA (Zhang HY et al., 2013; Zhou P et al., 2016). Previous findings demonstrated that when linear DNA interacts with the drug, the latter can be inserted into the DNA double helix between the base pairs; this could be followed by the formation of a number of spiral DNA molecular chains, which can be cut into many fragments (Nahid Shahabadi, 2011; Salerno D et al., 2010; Hou XM et al., 2009). Combine the results of UV-visible spectra, it indicated that the insertion binding was a major role in the interaction between gigantol and AR gene.

And, we used SERS to further research the mode of interaction between gigantol and the AR gene. Experimental studies in recent years showed that SERS allows the Raman scattering signal of the tested material enhancement $1014-1015$ times, and $10^{-7} \mathrm{M}$ of DNA can also be detected (Yang M et al., 2016; Kim S et al., 2016; Li Y et al., 2016; Vaverkova et al., 2014). In this experiment, the SERS peaks of AR gene were greatly enhanced with the increasing amounts gigantol. The mechanism of enhancement is ascribed to the appearance of resonance between AR 
gene and gigantol, based on the fact that the resonance enhancement should provide several orders of additional magnitude enhancement relative to the electromagnetic enhancement alone (Zhou H et al., 2015; Chakraborty SD et al., 2016).

\section{Conclusions}

In summary, in this research we provide new insights on the interaction of AR gene with gigantol extracted from Dendrobium chrysotoxum Lindl. Our preliminary data revealed that gigantol interacts with AR gene through intercalate into the DNA base pairs and does not groove Binding. This is the first report on gigantol-AR gene interactions, and the biological data acquired in the present research should be valuable for the rational drug design and greater clinical efficacy.

\section{Acknowledgments}

This study was supported by grants from the National Natural Science Foundation of China (81274157, 81102674, 30850012), Guangdong Natural Science Foundation (S2011010005661), Guangdong Science \& Technology Planning Project (2011B031700076, 2009B090300335), Guangzhou Science \& Technology Planning Project (2014J4100082) and the U.S. Department of Agriculture (USDA)/Agricultural Research Service (Cooperative Agreement No. 1950-5100-087). 


\title{
Authors' contribution
}

XYW(jidewowxy2@qq.com) was responsible for the design of the experiments;

JW(445741136@qq.com),XL(xiaoxuesnowflak@163.com),WFM(550517704@163.com) and

DC(1048456990@qq.com) were contribution to the most of the experimental operation;

WCW(wanwencheng@gzucm.edu) and QHY(297010172@qq.com) gave the guidance on experimental operation and the data statistic; JMH(hujiangmiao@mail.kib.ac.cn)was responsible for the extraction of Gigantol. JW and XL finished the writer of the article; OC (Oliver.Chen@tufts.edu) gave guidance to the modification of the article.

\author{
Abbreviations \\ DC, diabetic cataracts; \\ AR, aldose reductase; \\ HLECs, human lens epithelial cells; \\ APTES, aminopropyl triethoxysilane; \\ UV spectra, Ultraviolet-visible spectroscopy; \\ ETOH, Ethyl Alcohol; \\ ETOAC, ethyl acetate \\ MEOH, Methyl alcohol; \\ CC, column chromatography;
}

AFM, Atomic force microscope;

SERS, surface-enhanced raman spectroscopy;

RT-PCR, real-time reverse transcription polymerase chain reaction; 
MEM, minimum essential medium;

FBS, Fetal bovine serum;

PBS, phosphate-buffered saline;

IC50, half maximal inhibitory concentration

\section{Chemical compounds}

Gigantol (PubChem CID: 10221179);

D-Glucose (PubChem CID: 579);

3- Aminopropyl triethoxysilane (PubChem CID: 13521);

Penicillin (PubChem CID: 5904);

Streptomycin (PubChem CID: 19649)

ETOH, (PubChem CID: 702)

ETOAC, (PubChem CID: 8857)

MEOH, (PubChem CID: 887).

\section{References}

Agte, V., Gite, S., 2014. Diabetic Cataract and Role of Antiglycating Phytochemicals. Handbook of Nutrition, Diet and the Eye. 131-140.

Bahmani, F., Bathaie, S.Z., Aldavood, S.J., Ghahghaei, A., 2012. Glycine therapy inhibits the progression of cataract in streptozotocin-induced diabetic rats. Molecular Vision. 18, 439-448.

Bhummaphan, N., Chanvorachote, P., 2015. Gigantol Suppresses Cancer Stem Cell-Like 
Phenotypes in Lung Cancer Cells. Evid Based Complement Alternat Med. 2015, 1-10.

Banitaba, M.H., Davarani , S.S., Mehdinia, A., 2011. Study of interactions between DNA and aflatoxin B1 using electrochemical and fluorescence methods. Anal. Biochem. 411, 218-222.

Chakraborty, S.D., Sau, A., Kuznetsov, D.V., Banerjee, A., Bardhan, M., Bhattacharya, M., Dasgupta, D., Basu, S., Senapati, D., 2016. Development of a Triplet-Triplet Absorption Ruler: DNA- and Chromatin-Mediated Drug Molecule Release from a Nanosurface. J Phys Chem B, 120, 6872-6881.

Charoenrungruang, S., Chanvorachote, P., Sritularak, B., Pongrakhananon, V., 2014. Gigantol, a bibenzyl from Dendrobium draconis, inhibits the migratory behavior of non-small cell lung Cancer cells. J. Nat. Prod. 77, 1359-1366.

Chinese Pharmacopoeia Commission, 2010. Pharmacopoeia of the People's Republic of China. Chemical Medical Science Press, Beijing.

Chung, S.S., Chung, S.K., 2003. Genetic analysis of aldose reductase in diabetic complications. Current Med Chem. 10, 1375-1387.

Daikos, O., Naumov, S., Knolle, W., Heymann, K., Scherzer, T., 2016. Peculiarities of the photoinitiator-free photopolymerization of pentabrominated and pentafluorinated aromatic acrylates and methacrylates. Phys Chem Chem Phys, 18, 32369-32377.

Demaine, A.G., 2003. Polymorphisms of the aldose reductase gene and susceptibility to diabetic microvascular complications. Curr. Med. Chem. 10, 1389-1398.

Dehkordi, M.N., Bordbar, A.K., Lincoln, P., Mirkhani,V., 2012. Spectroscopic study on the interaction of ct-DNA with manganese Salen complex containing triphenyl phosphonium groups. Spectrochim Acta A. 90, 50-54. 
Fan, Y., Han, H., He, C., 2014.Identification of the metabolites of gigantol in rat urine by ultra-performance liquid chromatography combined with electrospray ionization quadrupole time-of-flight tandem mass spectrometry. Biomed.Chromotgr. 28, 1808-1815

Fang, H., Hu, X., Wang, M., Wan, W., Yang, Q., et al., 2015. Anti-osmotic and antioxidant activities of gigantol from Dendrobium aurantiacum var. denneanum against cataractogenesis in galactosemic rats. J. Ethnopharmacol. 172, 238-246.

Guo, Y.J., Chao, J.B., Pan, J.H., 2007. Study on the interaction of 5-pyridine-10, 15, 20-tris-(p-chlorophenyl) porphyrin with cyclodextrins and by DNA spectroscopy. Spectrochim Acta A. 68, 231-236.

Gao, E.J., Liu, Q., 2002. Study on the synthesis, anti-cancer activity and the interaction with DNA of compounds [Pd (L) (trp)] $\mathrm{Cl} \cdot 5 \mathrm{H} 2 \mathrm{O}$ ( $\mathrm{L}=$ phen, 5-NO2 phen). Acta Chim. Sin. 60, 674- 680.

Gudipudi, G., Venu, S., Shaym, p., Malini, D.A., Srinivas, B., Vijay, K.P., Prasad, R.C., G.L.David, K., Someswar, R., Sagurthi, D., 2016. Design and synthesis of chiral 2H-chromene-N-imidazolo-amino acid conjugates as aldose reductase inhibitors. Eur. J. Med. Chem. 124,750-762.

Henry, D.N., Monte, M.D., Greene, D.A., Killen, P.D., 1993. Altered aldose reductase gene regulation in cultured human retinal pigment epithelial cells. J. Clin. Invest. 92, 617-623.

Hou, X.M., Zhang, X.H., Wei, K.J., Ji, C., Dou, S.X., Wang, W.C., Li, M., Wang, P.Y., 2009. Cisplatin induces loop structures and condensation of single DNA molecules. Nucleic Acids Res., 37, 1400-1410.

Hu, J.M., Fan, W.W., Dong, F.W., Miao, Z.H., Zhou, J., 2012. Chemical Components of Dendrobium chrysotoxum. Chinese Journal of Chemistry. 30, 1327.-1330. 
Ibarki, N., Chen, S.C., Lin, L.R., Okamoto, H., Pipas, J.M., Reddy, V.N., 1998. Human lens epithelial cell line. Exp Eye Res. 67, 577-85.

Judy, D.R., Stanley, N.G., 1986. Effects of magnesium on galactose-induced cataract formation and lens aldose reductase activity in rats. Nutrition Research. 6,699- 708.

Jaumot, J., Gargallo, R., 2012. Experimental Methods for Studying the Interactions between G-Quadruplex Structures and Ligands.Curr. Pharm. Des. 18, 1900 - 1916.

Kang, Q.Q., Zhou, G.M., 2012. Study of aspirin and its interaction with DNA by Raman and UV spectroscopies. Guang Pu Xue Yu Guang Pu Fen Xi. 32, 699-702.

Kim, S., Jeong, S.N., Bae, S., Chung, H., Yoo, S.Y., 2016. Sensitive Surface Enhanced Raman Scattering-Based Detection of a BIGH3 Point Mutation Associated with Avellino Corneal Dystrophy. Anal Chem. 88, 11288-11292.

Kinoshita, J.H., 1990. A thirty year journey in polyol pathway. Exp. Eye. Res. 50, 567-73.

Li, X., Shen, Y., Lu, Y., Yang, J., 2015. Amelioration of bleomycin-induced pulmonary fibrosis of rats by an aldose reductase inhibitor. Epalrestat. Korean J. Physiol Pharmacol. 19, 401-411.

Li, Y., Zhao, Q., Wang, Y., Man, T., Zhou, L., Fang, X., Pei, H., Chi, L., Liu, J., 2016. Ultrasensitive Signal-On Detection of Nucleic Acids with Surface-Enhanced Raman Scattering and Exonuclease III-Assisted Probe Amplification. Anal Chem. 88, 11684-11690. Minassian, D.C., Mehra, V., 1990. 3.8 Million binded by cataract each year: projections from the first epidemiological study of incidence of cataract blindness in India. Br. J. Ophthalmol. 74, 341-3.

Miyamoto, S., 2002. Recent advances in aldose reductase inhibitors: potential agents for the treatment of diabetic complications. Expert Opin. Ther. Patents. 12, 621-631. 
Nahid, S., Somaye, M., Robabeh, A., 2011. DNA Interaction Studies of a New Platinum(II) Complex Containing Different Aromatic Dinitrogen Ligands. Bioinorganic Chemistry and Applications. 2011, 429241-8

Nasir, N., Agarwal, R., Tripathy, M., Alyautdin, R., Ismail, N.M., 2013.Tocotrienol delays onset and progression of galactose-induced cataract in rat. Acta Pharmacologica Sinica. 34, 147.

Niu, M.J., Li, Z., Chang, G.L., Kong, X.J., Hong, M., Zhang, Q.F., 2015. Crystal Structure, Cytotoxicity and Interaction with DNA of Zinc (II) Complexes with o-Vanillin Schiff Base Ligands. PloS one. 10, 1-14.

Ouameur, A.A., Marty, R.,Tajmir- Riahi, H.A., 2005. Human serum albumin complexes with chlorophyll and chlorophyllin. Biopolymers. 77, 129-136.

Pascolini, D., Mariotti, S.P., 2011. Global estimates of visual impairment: 2010. Br. J. Ophthalmol. 95, 614-8.

Pan, L.H., Li, X.F., Wang, M.N., Zha, X.Q., Yang, X.Q., Liu, A.J.,et al., 2014. Comparison of hypoglycemic and antioxidative effects of polysaccharides from four different Dendrobium species. Int. J. Biol. Macromol. 64, 420-427.

Pakravan, P., Masoudian, S., 2015. Study on the Interaction between IsatinThiosemicarbazone and Calf Thymus DNA by Spectroscopic Techniques. Iran. J. Pharm. Res. 14, 111-123.

Pokharel, G.P., Regmi, G., Shrestha, S.K., Negrel, A.D., Ellwein, L.B., 1998.Prevalence of blindness and cataract surgery in Nepal. Br. J. Ophthalmol. 82, 600-5.

Prasad, A., Raju, G., Sivalingam, V., Girdhar, A., Verma, M., Vats, A., Taneja, V., Prabusankar, G., Patel, B.K., 2016. An acridine derivative, [4, 5-bis $\{(\mathrm{N}$-carboxy methyl imidazolium $)$ methyl\} acridine] dibromide, shows anti-TDP-43 aggregation effect in ALS disease models. 
Sci Rep. 6, 39490.

Rao, G.N., Khanna, R.C., Payal, A., 2011. The global burden of cataract. Curr. Opin. Ophthalmol. 22, 4-9.

Salerno, D., Brogioli, D., Cassina, V., Turchi, D., Beretta, G.L., Seruggia, D., Ziano, R., Zunino, F., Mantegazza, F., 2010. Magnetic tweezers measurements of the nanomechanical properties of DNA in the presence of drugs. Nucleic Acids Res., 38, 7089-7099.

Shao, G., Qian, D., Wang, H., Yan, Z., Hu, M., Wang, T., Wang, B., 2015. Construction of the plasmid coding for the expression of the EGFP-M-IL-2(88Arg, 125Ala) fusion protein and the anti-tumor effects exerted by the fusion protein in HeLa-60 cells. 9, 2729-2735.

Srinivasan, V., Radha, A., Schmidt, A.M., Ramasamy, R., 2012. Aldose reductase, oxidative stress and diabetic cardiovascular complications. Cardiovasc Hematol Agents Med Chem. $10,234-240$.

Susen, S., Buyukbingol, E., 2003. Recent studies of aldose reductase enzyme inhibition for diabetic complications. Curr. Med. Chem. 10, 1329-1352.

Tysoe, S.A., Morgon, R.J., Baker, T.C., Strekas, T.C., 1993. Spectroscopic investigation of differential binding modes of delta and lambdaru(bpy)2(ppz)2+ with calf thymus DNA. J. Phys. Chem. 97, 1707-1711.

Vaverkova, V., Vrana, O., Adam,V., 2014.The Study of Naphthoquinones and their Complexes with DNA by Using Raman Spectroscopy and Surface Enhanced Raman Spectroscopy: new insight into Interactions of DNA with Plant Secondary Metabolites. Bio. Res. Int. 2014, 461393

Wang, Y., Luk, A.O., Ng, M.C., Pang, C.C., Lam, V., Lee, S.C., Lam, D.S., Choy, K.W., Ma, R.C., So, W.Y., Chan, J.C., 2014. Additive effect of aldose reductase Z-4 microsatellite 
polymorphism and glycaemic control on cataract development in type2 diabetes. J Diabetes Complications. 28,147-151.

Wild, S., Roglic, G., Green, A., Sicree, R., King, H., 2004. Global prevalence of diabetes. Diabetes Care. 27, 1047-53.

Wu, J., Lu, C., Li, X., Fang, H., Wan, W., Yang, Q.,et al, 2015.Synthesis and Biological Evaluation of Novel Gigantol Derivatives as Potential Agents in Prevention of Diabetic Cataract. PLoS ONE. 10, 1-14.

Xu, J., Wu, Z.S., Wang, Z., Le, J., Zheng, T., Jia, L., 2016. Autonomous assembly of ordered metastable DNA nanoarchitecture and in situ visualizing of intracellular microRNAs. Biomaterials, 120, 57-65.

Yabe-Nishimura, C., 1998. Aldose reductase in glucose toxicity: a potential target for the prevention of diabetic complications. Pharmacological Reviews. 50, 21-33.

Yang, M., Zhang, L., Chen, B., Wang, Z., Chen, C., Zeng, H., 2016. Silver nanoparticles decorated nanoporous gold for surface-enhanced Raman scattering. Nanotechnology. 28,055301 .

Yang, L.,Qin, L.H., Bligh, S.W., Bashall, A., Zhang, C.F., Zhang, M., Wang, Z.T., Xu, L.S., 2006. A new phenanthrene with a spirolactone from Dendrobium chrysanthum and its anti-inflammatory activities. Bioorg. Med. Chem. 14, 3496-3501.

Zhang, H.Y., Liu, Y.R., Ji, C., Li, W., Dou, S.X., Xie, P., Wang, W.C., Zhang, L.Y., Wang, P.Y., 2013. Oxaliplatin and its enantiomer induce different condensation dynamics of single DNA molecules. PLoS One, 12, e71556.

Zhang, J., Li, X., Sun, X., Li, Y., 2005. Surface Enhanced Raman Scattering Effects of Silver 
Colloids with Different Shapes. J. Phys. Chem. B. 109, 12544-12548.

Zheng, W.C., 2006. The application of atomic force microscopy in DNA research. Modern instrument, 1, 9-12.

Zhou, H., Lin, S., Nie, Y., Yang, D., Wang, Q., Chen, W., Huang, N., Jiang, Z., Chen, S., 2015. Surface-enhanced resonance Raman scattering (SERRS) simulates PCR for sensitive DNA detection. Analyst, 140, 7518-7521.

Zhou, P., Yu, H., Shi, J., Jiao, N., Wang, Z., Wang, Y., Liu, L., 2016. A rapid and automated relocation method of an AFM probe for high-resolution imaging. Nanotechnology, 27, 395705. 


\section{Figure legends}

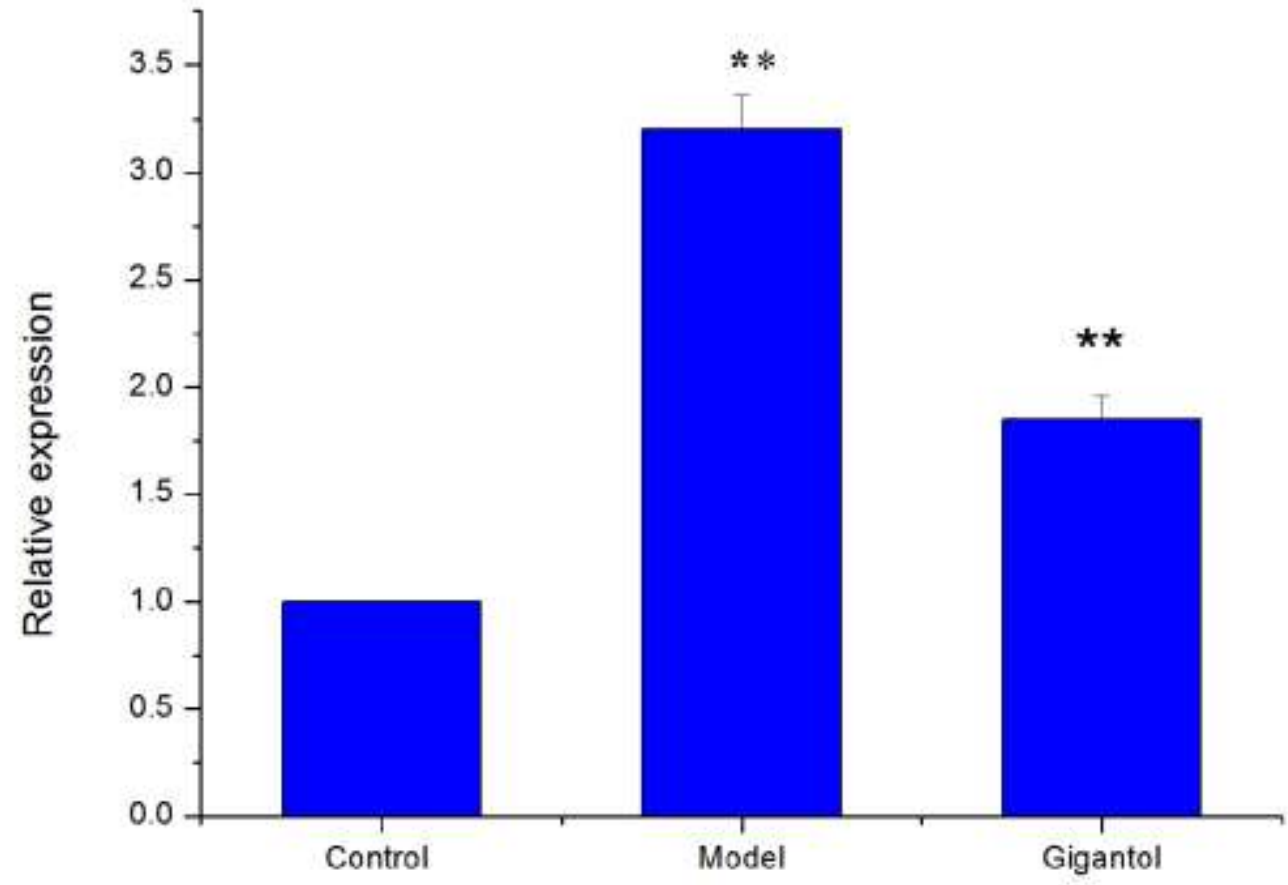

Fig.1. Expression of AR gene in HLECs

The relative levels of AR gene expression in different group, and it was measured by real-time PCR. Results are shown as mean $\pm \mathrm{SD}(\mathrm{n}=6) ; *(\mathrm{P}<0.05), * *(\mathrm{P}<0.01)$ 


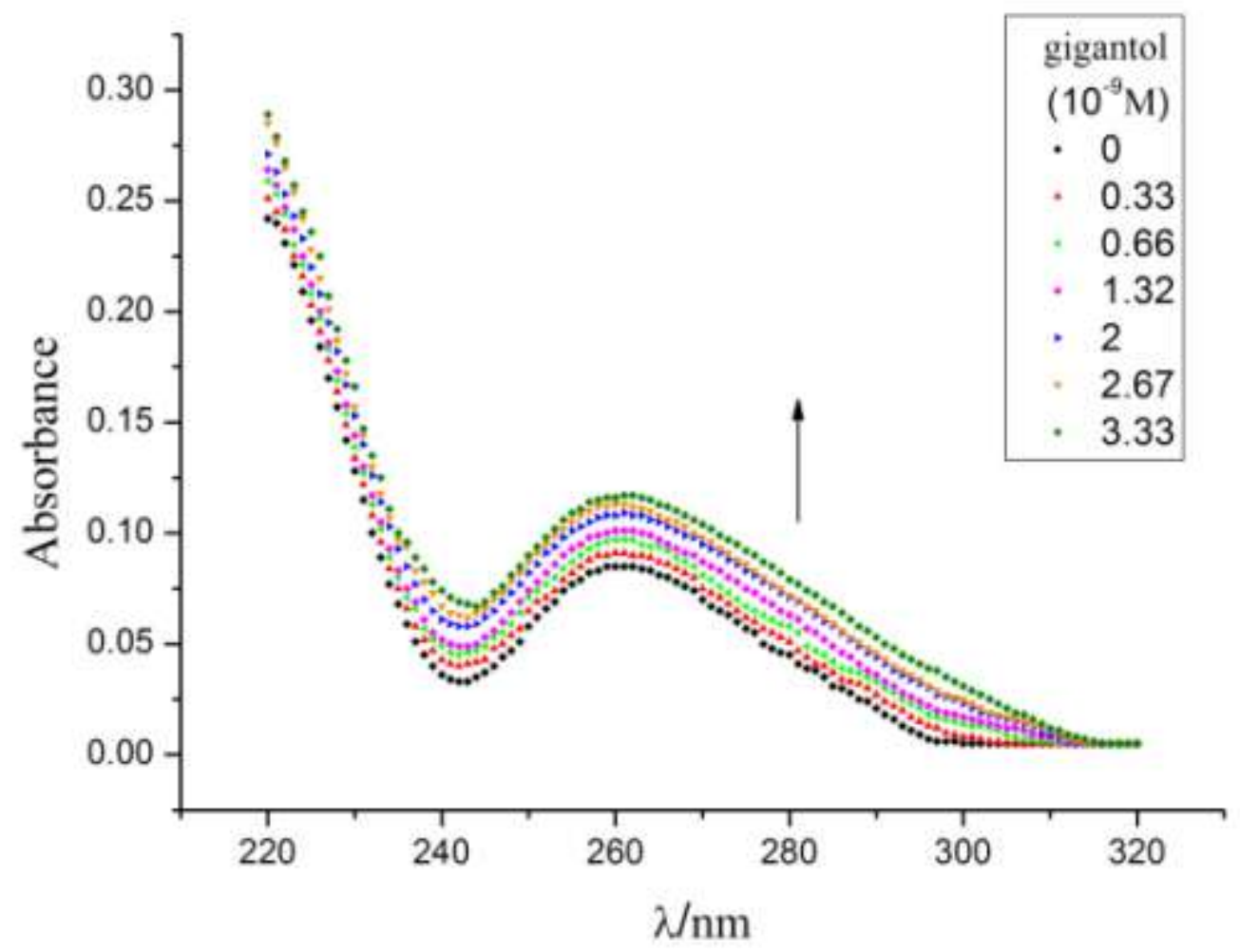

Fig.2. UV-visible spectroscopy of AR gene in 0.01M Tris-Hcl buffer (PH7.4) at room temperature in the presence of increasing amounts gigantol. The concentration of AR gene was $10^{-7} \mathrm{~mol} / \mathrm{L}$, and the concentration of gigantol was $0,0.33,0.66,1.32,2,2.67$, $3.33 \times 10^{-9} \mu \mathrm{M}$ from bottom to the top. Arrows indicated the change in absorbance upon increasing the gigantol concentration. 


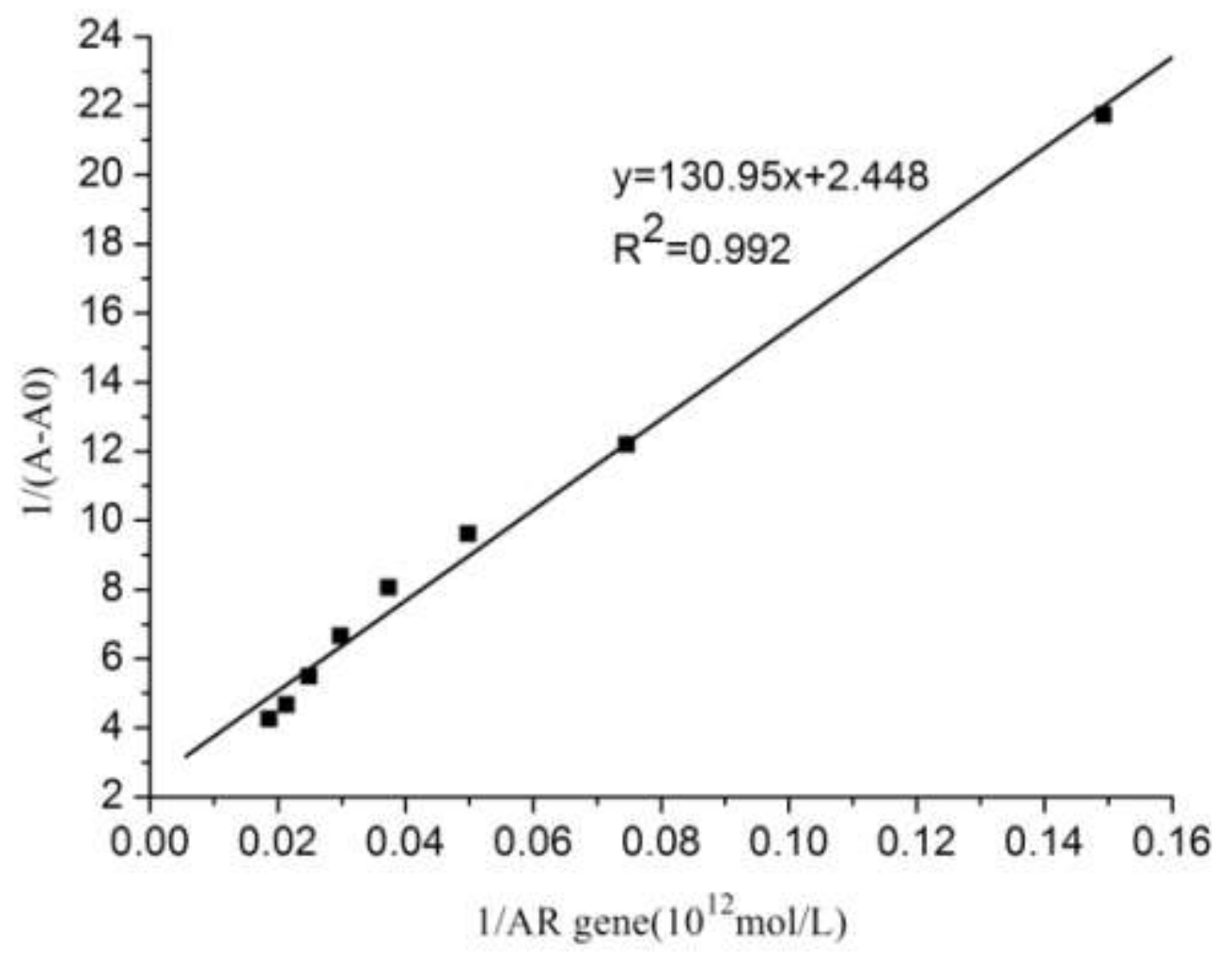

Fig.3.The plot of 1/(A-A0) vs. 1/[AR gene] for AR and its complexes with gigantol, where A0 is the initial absorption band of free AR gene $(280 \mathrm{~nm})$ and A is the recorded absorption band at different gigantol concentrations. 

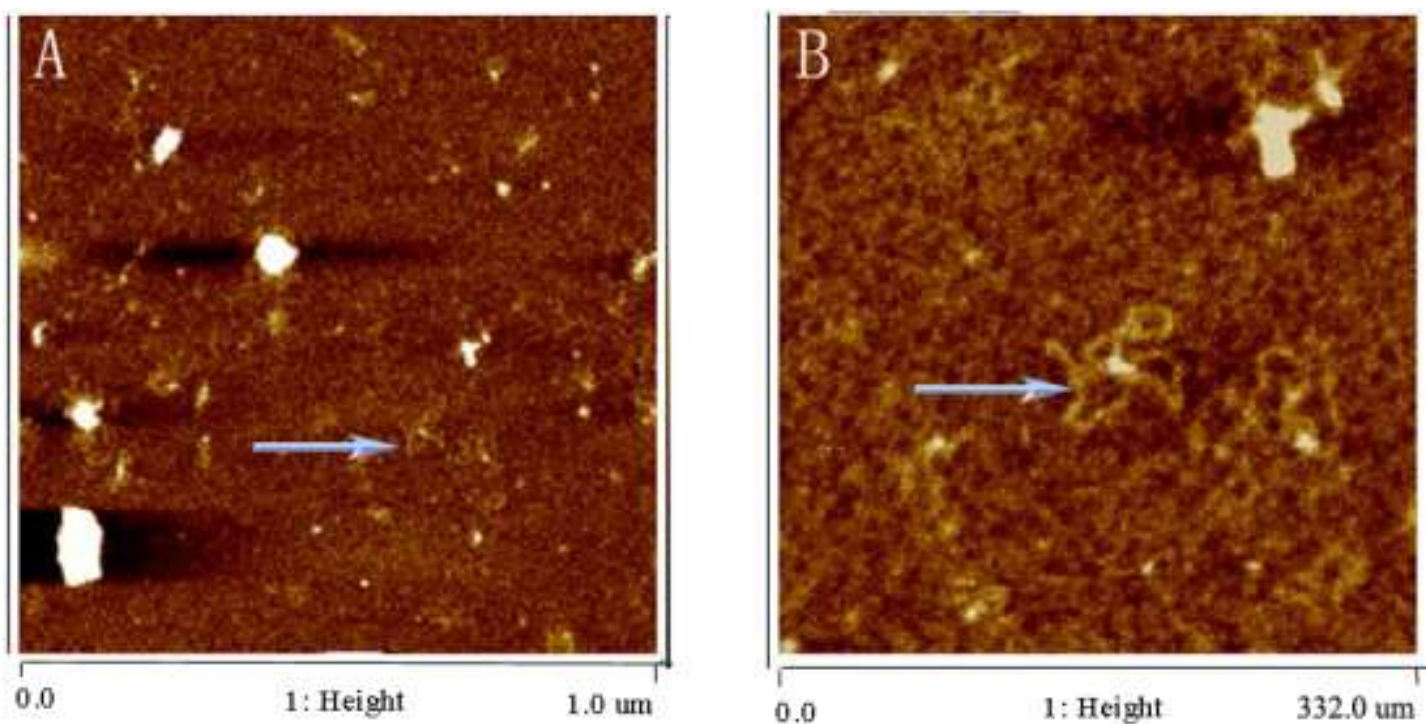

Fig.4. The surface topography of AR gene was assessed by AFM under the natural state.

A, B were the images of AR gene at different amplification factor: A $1 \times 1 \mu \mathrm{m}$; B $332 \times 332 \mathrm{~nm}$. The AR gene has some winding in natural sedimentation and APTES adsorption, and the arrows indicated the AR gene. 

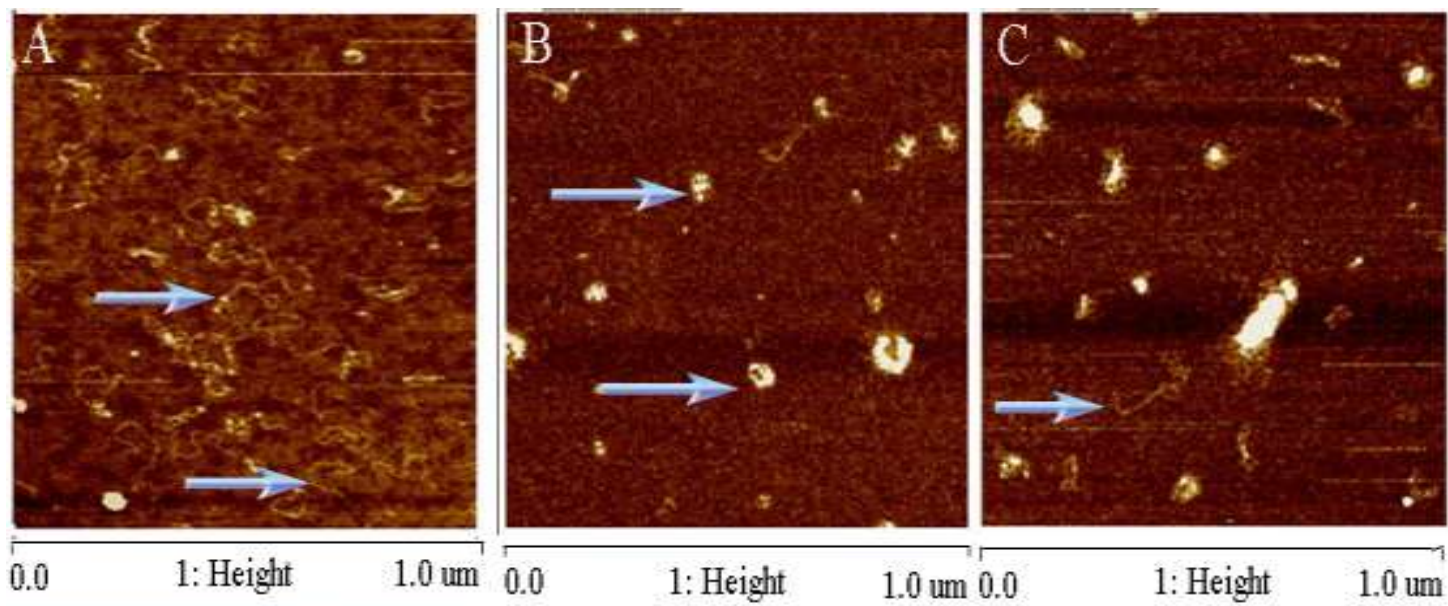

1: Height

1.0 um 0.0

1: Height

$1.0 \mathrm{um}$
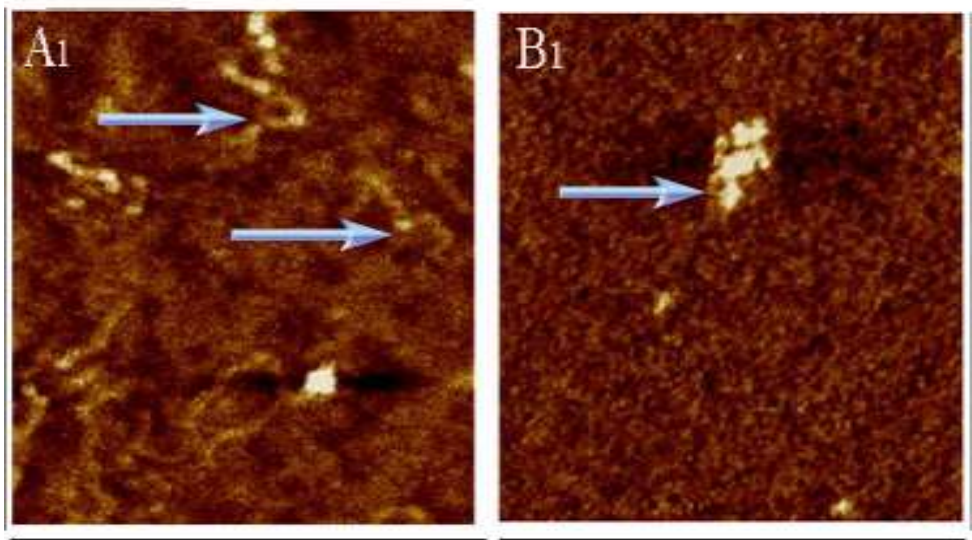

0.0

1: Height

$378.9 \mathrm{~nm} 0.0$

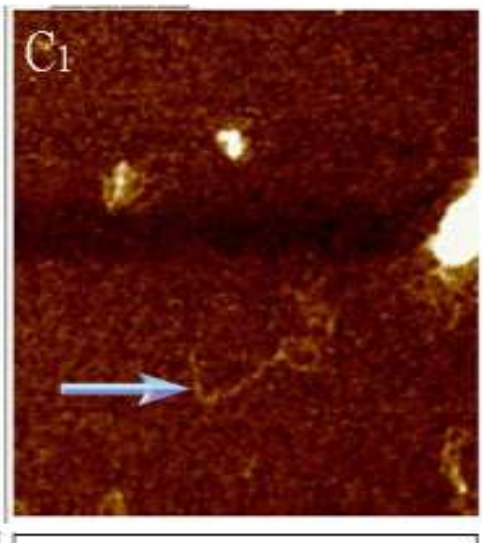

1: Height

$350.2 \mathrm{~nm} 0.0$

1: Height $503.9 \mathrm{~nm}$

Fig.5. The images of AR gene with Gigantol at different concentrations interaction assessed by AFM. A and A1, B and B1, C and $\mathrm{C} 1$ were the images of gigantol at different concentrations of $10^{-6} \mathrm{M}, 10^{-5} \mathrm{M}, 10^{-4} \mathrm{M}$, respectively. A, B, C, and A1, B1, C1were the images of AR gene at different amplification factor: A, B, C $1 \times 1 \mu \mathrm{m}$; A1 $378 \times 378 \mathrm{~nm}, \mathrm{~B} 1350.2 \times 350.2 \mathrm{~nm}$ and C1 503.9×503.9nm.All images were acquired in tapping mode in liquid. Arrows indicated the AR gene. 


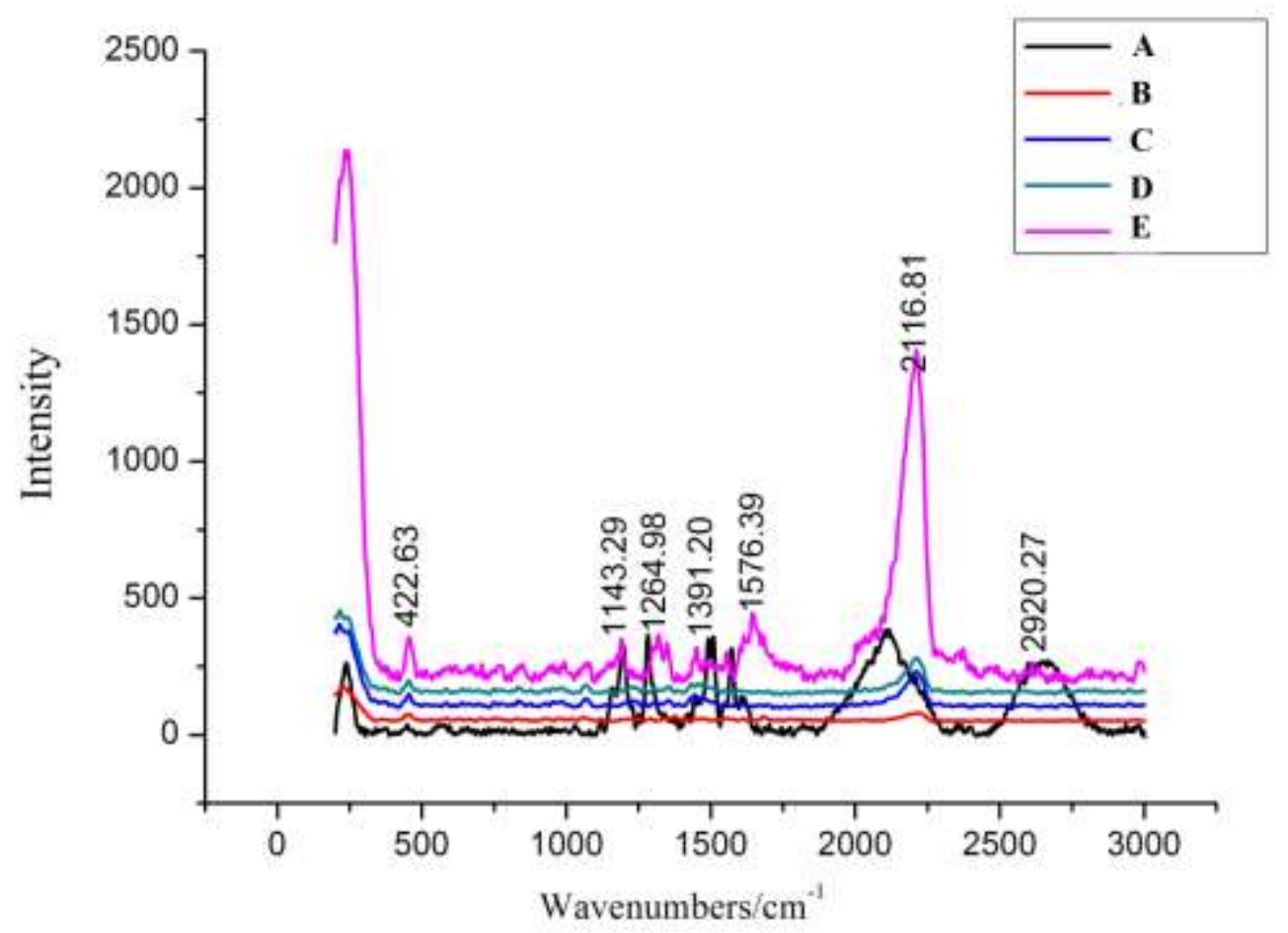

Fig.6. Raman spectra of the AR gene in gigantol at different concentrations gigantol $\mathrm{A}, \mathrm{B}, \mathrm{C}, \mathrm{D}$ and $\mathrm{E}$ were the images of $\mathrm{AR}$ gene, gigantol, and $\mathrm{AR}$ gene in gigantol at different concentrations of $10^{-7} \mathrm{M}, 10^{-6} \mathrm{M}$, and $10^{-5} \mathrm{M}$, respectively. 
Table 1

Oligonucleotide primer pairs used for PCR assay

Target gene Primer designation Nucleotide sequence $5, \rightarrow 3$,

\begin{tabular}{llc}
\hline AR gene & AR-BgIII $(\mathrm{F})$ & GAAGATCTATGGCAAGCCGTCTCCTG \\
& Ard-EcoRI (R) & CGGAATTCTAAACTCTTCATGGAAGGGGT \\
\hline
\end{tabular}




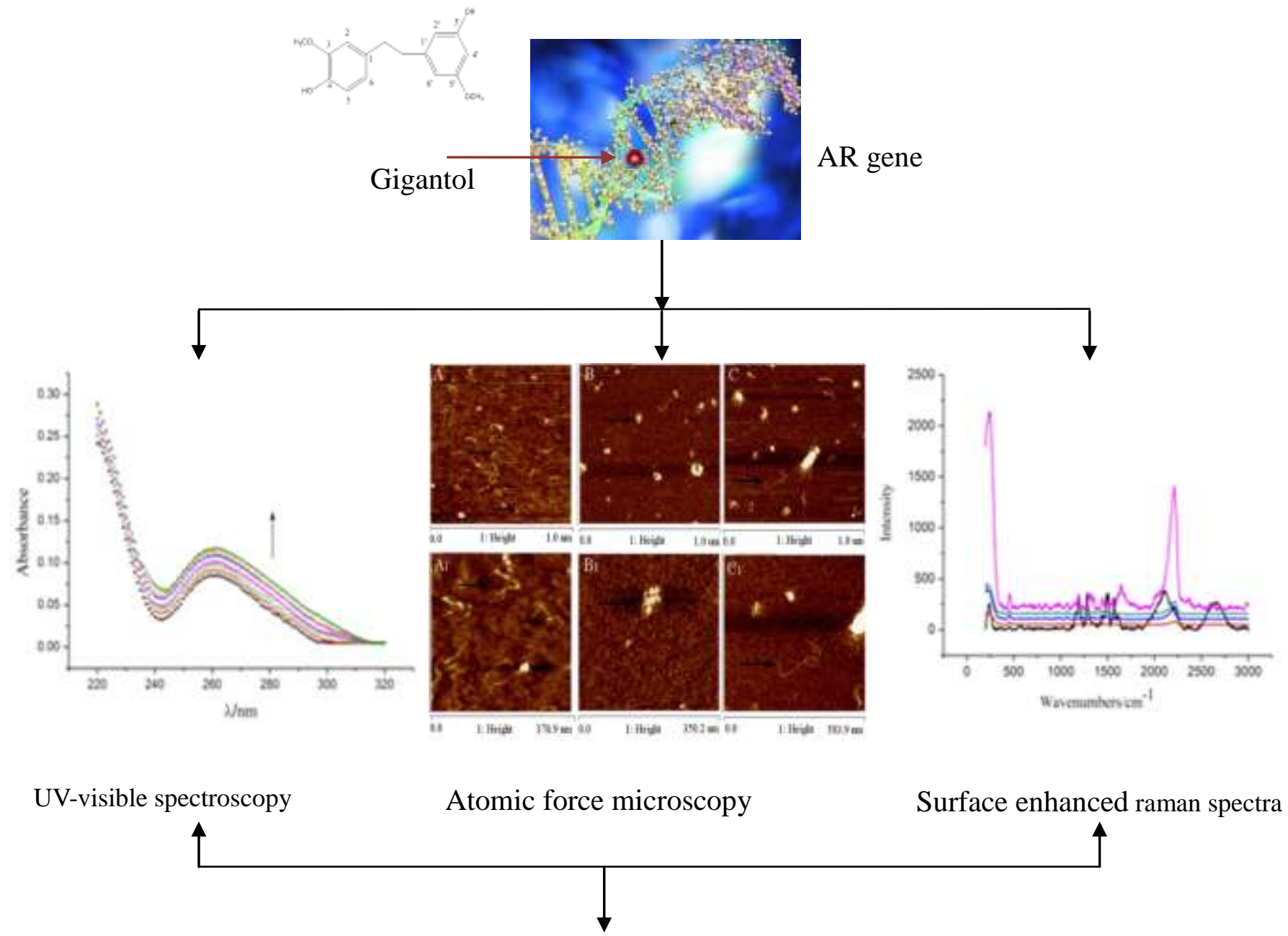

Gigantol interacts with AR gene through intercalate into the DNA base pairs and does not groove Binding, and the hindino constant was calculated to he $185 \times 10^{3} \mathrm{I} / \mathrm{mol}$ 